\title{
The Diffusion of Identity: A Study of Three Contemporary Thai Short Stories through the Lens of Western Narrative Conventions
}

\author{
Sean Ford \\ Assistant Professor, Department of English, Faculty of Humanities, \\ Chiang Mai University, Chiang Mai, Thailand \\ ford.sean@cmu.ac.th
}

\begin{abstract}
Literary works give expression to universal themes through settings, subjects, and techniques that are culturally tied. This article reviews generic conventions involving point of view, protagonist, conflict, rising action, climax, falling action, and resolution that typify Western short stories in order to examine how varying patterns can illuminate cultural contrasts between Thailand and the West. Widely known stories by Katherine Mansfield and Amy Tan serve to exemplify the conventional Western pattern and its versatility and to provide a basis for discovering alternative patterns that characterize numerous contemporary Thai short stories. An analysis of stories by S.E.A. Write award winners Phaitoon Thanya, Anchan, and Ussiri Thammachot through the comparative lens of Western conventions reveals how divergent narrative techniques involving point of view and plot elucidate and corroborate divergent expressions regarding the nature of identity. Narrative patterns in these Thai short stories help produce diffusions of identity that reflect a collectivist ethos and an acceptance of uncertainty and impermanence, while adherence to the Western formula reinforces a core belief in the permanence and persistence of the individual ego over time.
\end{abstract}

\section{Keywords}

Thai short stories - Western literary conventions - Phaitoon Thanya (Thanya Sangkapanthanon) - Anchan (Anchalee Vivatanachai) - Ussiri Thammachot 
This study offers an analysis of a selection of Thai short stories published after 1976, the year of the "rightist massacre" (Pattarakulvanit 2014, 148) at Thammasat University in Bangkok. Recent English language scholarship about Thai literature frequently uses this date as a demarcation for studying trends developing in the decades after the coup. Herbert P. Phillips and his associates $(1987,58)$, who collected translations with accompanying "ethnographic interpretations" of a wide range of Thai literary works published between 1960 and 1976, had already discerned an emergent "strain" of literature comprising works that "analyze and clarify human problems or conditions" without offering moral pronouncements. Such works, they suggest, allow readers to "make up their own minds about how such problems are to be resolved - if they are to be resolved at all" $(1987,58)$. A decade later, in his study of post-1976 works, Chetana Nagavajara $(1998,75)$ identifies a literature of "social consciousness" that "merely poses problems, and does not provide clear answers."

Often framed by both socio-cultural and Thai literary contexts, scholarship over the last two decades ranges from explorations of problems in translation to linguistic, textual, comparative, and theoretical analyses. Disturbing Conventions: Decentering Thai Literary Studies (2014), a recent collection by Thai and non-Thai scholars, begins to situate Thai literature within a global framework by means of "so-called Western" theoretical approaches. The present study applies an analytical Western approach to Thai stories, but it does so to uncover difference. Instead of adopting a socio-cultural or theoretical framework or privileging literary themes or topics, it foregrounds long-established narrative techniques that characterize the genre of the short story. The analysis employs a comparative framework by using conventional patterns of the Western short story to bring to light divergent patterns in contemporary Thai short stories and to explore the roles these patterns play in revealing and reflecting cultural attitudes and traits, particularly with regard to the nature of identity.

Four commonly noted features of recent Thai literature also inform this study: a focus on ordinary people and situations (Harrison 1999; Nagavajara 1998; Pattarakulvanit 2014; Phillips 1987), a concern with contemporary social

1 This article stems from a paper presented at the Huachiew Chalermprakiet University 6th National and International Conference on June 22, 2018. An early, much condensed, version of the core idea was published in the official proceedings of that conference under the title "Whose Story is it in the End?: Narrative Techniques in Some Contemporary Thai and Western Short Stories." 
problems (Harrison 1999; Nagavajara 1998; Pattarakulvanit 2014; Prachakul 2014), the influence of tradition, including especially the centrality of Buddhism (Harrison 1999, 2014; Kepner 1996), and a treatment and style characterized by subtlety, ambiguity, and moral uncertainty (Nagavajara 1998; Phillips 1987). This study also carries forward two more particular observations made by Phillips regarding Thai literature between 1960 and 1976. He found evidence of both a "tolerance for uncertainty and ambiguity in interpersonal situations" $(1987,154)$ and a "stoical, non-Faustian, and thoroughly realistic acceptance of personal failure and death as inherent and omnipresent features of the human experience" $(1987,30)$.

Within the context outlined above, the ensuing discussion approaches Thai short stories through techniques of textual analysis. In particular, the study uses familiar conventional narrative features of Western short stories as a lens for identifying demonstrably alternative features in numerous modern and contemporary Thai short stories by first presenting two well-known Western stories that typify conventional and recurring patterns regarding point of view and plot, then setting these patterns against a selection of Thai stories to highlight stark differences in the patterns of their counterparts. An examination of stories by Phaitoon Thanya, Anchan, and Ussiri Thammachot, concentrating on elements of craft, uncovers striking variations of generic characteristics common to the genre of the short story, which, in turn, help elucidate thematic preoccupations, corroborate cultural attitudes toward being or existence, and offer insight into and appreciation for divergent cultural tendencies between Thailand and the West.

\section{Exemplars of the Western Pattern}

Conventions that help to characterize and define literary genres also help to shape expectations of readers and vice versa. Over the last two centuries, the Western short story has developed narrative patterns that are repeated with great regularity despite tremendous variety in theme, subject, style, and expression produced by many culturally various practitioners of the form. These practitioners, time and again, draw from the well of established convention both to satisfy and surprise the expectations of readers who form the counterpart to the development of the genre. Consciously or unconsciously, Western readers bring certain expectations regarding characterization, setting, point of view, and plot to their encounters with individual stories, and the action of the stories advances in an interplay between the precedent of convention and the immense variability that may be created out of it. This study focuses on the 
particular relationships that Western stories repeatedly orchestrate between a story's point of view and its protagonist and between a story's protagonist and its elements of plot. A presentation of these relationships in two widely anthologized stories will establish a basis for observing and analyzing contrasting patterns found in many modern and contemporary Thai short stories.

"Miss Brill," first published in 1920 by New Zealand-born Katherine Mansfield $(2015,862-865)$, tells the story of an elderly English lady in France who spends her Sunday afternoons people-watching in the park. The story is narrated from a third-person point of view through which Mansfield intimately portrays the world of Miss Brill entirely as Miss Brill sees and experiences it-her observations, thoughts, and feelings. Mansfield's particular form of limited omniscience verges on "stream of consciousness," described by Ann Charters (2015, 1744) as the "technique by which an author attempts to capture the flow of a character's thoughts." This particular Sunday Miss Brill experiences a growing sense of awareness that everyone around her is involved in an interconnected performance and that everyone has a part, including her. The plot line, centered on Miss Brill's internal commentary upon the sights and sounds and people around her, shares a unique feature of numerous Mansfield stories, including two of her other most-anthologized pieces, "The Garden Party" and "Bliss." Many of Mansfield's stories create a sense that something is going to happen, but they advance without explicitly identifying an element of conflict. Delimited by the perspective of a character who is unaware or only partly aware of the conflict, Mansfield's point of view functions to simultaneously mask and reveal it. The conclusions of these stories reveal that conflict has been ever present. This narrative strategy has the effect of both merging readers with the story's protagonist and granting readers insights that are withheld from the narrower self-awareness of the central character. The strategy also leaves no doubt as to who a story's protagonist is.

In this instance, Miss Brill's growing sensations of connectedness simultaneously reveal to readers her isolation and disconnection, though Miss Brill does not seem to see herself this way. The conflict, unrecognized by Miss Brill, appears to find a resolution by means of an epiphany regarding human interconnectedness that coincides with her heightened sensations. A young couple occupies the bench beside her and she imagines them to be the hero and heroine of the play, young lovers entered upon the stage to bring together and give meaning to all the various activities in the park. Their arrival, to Miss Brill, completes the growing sense of unity and human interconnection she believes she has been experiencing. Her eyes fill with tears at the coalescence of her sensations and this moment marks the clear climax or "emotional high point" (Charters 2015, 1677) of the story. However, the boy and girl make rude remarks 
about her-he refers to her as "a stupid old thing" (Mansfield 2015, 865). To them, she is an unwelcome voyeur to their crude sexual urges and expressions. Thus, they shatter her sense of human communion just on the brink of its perfect fulfillment. She walks home to her tiny apartment, passing the bakery where she usually stops to buy a treat. Alone in her room, Miss Brill hears the sound of "something crying" (Mansfield 2015, 865).

"Miss Brill" is appreciated for its nuanced and complex treatment of character, for the role that setting plays in characterization, and for the sophistication of its point of view, which limits the action to the perspective of a single character but also generates meaning beyond that character's limited view. Despite the idiosyncrasies of Mansfield's craft, the story iterates basic features of the Western formula: It centers on a single protagonist, identified by and with the story's point of view. It dramatizes a conflict concerning the protagonist (her loneliness and isolation) by means of rising action (growing activity in the public gardens and her growing sense of connectedness), climax (her illusionary epiphany), falling action (the tumbling of her fantasy world), and resolution (she is very much alone). Close inspection and repeated readings of the story reveal that there is nothing random and nothing extraneous. The achievement of "Miss Brill" and other Mansfield stories, in fact, arises from her ability to forge originality within convention. Nothing is random or extraneous to the extent that the elements interrelate and reproduce the Western formula. The unique conformity of "Miss Brill," its variation within convention, shows forth all the more clearly when viewed alongside a very different exemplar of the Western formula.

"Two Kinds," first published in 1989 by Chinese-American author Amy Tan $(2015,1232-1240)$, is a remarkably different kind of story in terms of its plot line, characterization, conflict, resolution, and manner of telling. In first-person point of view, Amy Tan's protagonist Jing-mei looks back upon a childhood conflict with her mother that they never fully resolved. Retrospective first-person narration is very common in Western stories and creates terms of access radically different from the insistent present tense stream of consciousness technique of "Miss Brill." Tan uses the mode in conventional ways. It allows her narrator to adopt the storytelling pose, which creates meaningful distance between the events told and the actual telling. Tan's narrator-protagonist is thereby able to articulate the conflict early on and in the compact sophisticated fashion that maturity and hindsight make possible. Thus, while readers of "Miss Brill" come to identify the story's true source of conflict and its ironic climax only by reaching the end of the story (or upon a subsequent reading), readers of "Two Kinds" grasp the conflict from the start and watch it unfold. Jing-mei's retrospective gaze allows her to understand the conflict in both 
concrete and abstract terms. It is situated between a daughter and a mother-between a daughter's quest to assert her independence and determine her own identity and a mother's wishes for her daughter's success and the firm belief in this possibility. And it also thematizes competing variants of the American dream. Personal and ideological significances are simultaneously played out through the story's plot.

Jing-mei traces the rising action by recounting her mother's various attempts to make her into a child prodigy. Her mother ultimately fixes her shaping efforts upon piano lessons that culminate a year or so later in Jing-mei's disastrous performance at a talent show. The climax occurs the following day when Jing-mei shouts "I wish I'd never been born! . . . I wish I were dead! Like them" (Tan 2015, 1238). Her reference to the babies her mother lost back in China simultaneously raises personal and ideological conflicts to an emotional height. Falling action occurs over the passage of several decades and carries the story from the past into the present. In a gesture of reconciliation, Jing-mei's mother gifts the piano to her daughter on the occasion of her daughter's thirtieth birthday. The maternal gesture represents an incomplete resolution, a partial reconciliation that is completed by the final scene of the story. Jing-mei, the mature woman whose mother is now dead, sits down to the piano once again, for the first time in all those intervening years. On the facing pages of musical notation preserved from her childhood she now recognizes two companion pieces and she realizes that, when played together, these variations on a theme complete one another. Thus, the conflicts of "Two Kinds" are resolved by the first-person narrator through both her controlled manner of telling and her own understanding of the significance of the final scene. By contrast, Miss Brill's conflict is resolved for her by the intimacies and distances shaped by its very different point of view whereby both the conflict and its sad outcome are more comprehensible to readers than they are to Miss Brill.

\section{Divergent Patterns in Thai Short Stories}

"Miss Brill" and "Two Kinds" come from different periods and cultures and depart radically from one another in theme, subject, setting, character, point of view, temporal duration, and outcome; yet each story perfectly enacts the conventional Western formula. A central protagonist is the vehicle for the main conflicts, rising action, climax, falling action, and resolution, and a clear climactic moment leads logically to an ending. Point of view, whether first-person or third, intimate or distant, is aligned with the story's protagonist. Resolution, 
whether happy or sad and whether the protagonist realizes it or not, promises to change her in a significant or permanent way. Not all Western stories conform to this formula, but the vast majority do. It has proven to be extremely versatile and conducive to endless innovations that satisfy readers time and again. Many Thai stories, by contrast, are guided by narrative patterns that deviate from this formula in revealing ways. Instances can be found among the pre-1976 sources in Phillips (1987) and in numerous recent works. A close analysis of stories by S.E.A Write award winning authors Phaitoon Thanya, Anchan, and Ussiri Thammachot brings to light meaningful and illuminating divergences from the Western pattern. Each story in its own way decenters Western notions of the protagonist, displaces the fixture of the climax, and dismisses the urge to achieve resolution.

Phaitoon Thanya's "Paper Bird," translated by Tom Glass (2001, 31-47), first published in 1991, introduces readers to a humorless, angry, egotistical story writer who blames two boys at play for disturbing his genius. Such a condensed summation of the story is perfectly fair to its simple plotline. So too the suggestion that the writer is the story's central character. But is the nameless writer actually the story's protagonist? In the Western sense yes but then again no. Opening with a vocalized expletive, Thanya places him at his writing table, and projects his thoughts and attitudes through interior monologue using third-person point of view:

\section{"Dammit!"}

He ripped the paper from the typewriter, crumpled it up, and threw it in the basket beside the table. In the last half-hour, he had thrown away at least ten other sheets. But that was nothing compared to the way his ideas had been destroyed. His writing had gone nowhere today, and now his concentration was shot. His anger mounted. He needed to kick someone. (Thanya 2001, 31)

Such an opening would be perfectly standard for a Western story, too, and this common manner of narration proceeds for some time. But by the end of the story, the viewpoint shifts. The plot is divided into two confrontations between the writer and the boys playing outside. In the first, he damages and steals their paper bird and returns inside to write. In the second, he crushes a second paper bird in his fist, goes back inside, and disappears altogether. At this point, the plot shifts completely to the boys. They share their impressions of what's wrong with the enraged man, then start to walk away together, but ultimately their states diverge. The older boy is resolved to turn towards the future, while the younger boy remains fixated on the past. The story ends with the younger 
boy "staring ahead, deep in thought," "pounding his fist into the palm of his other hand, ready to fight" (Thanya 2001, 47).

The story connects its three characters in intricate ways. They share the creative or artistic impulse. Paper represents a blank slate on which to shape or imprint human creations and by this device birds and stories become symbols for one another. The younger boy "ready to fight" (Thanya 2001, 47) and the older writer in his constant simmering anger, who "needed to kick someone" (Thanya 2001, 31), are also inverted reciprocal symbols. A child whose soaring imagination gets trampled by the adult world has its counterpart in a bitter adult who blames his failed ambitions on the distractions of the everyday world outside his window. The ending prefigures the boy as the future angry writer and, in so doing, also figures the past childhood of the now angry adult. But these mirrorings are only potential. The story does not declare that this boy will become that man or that this man was once that little boy. Nor does it indicate whether the boy's emotional state will constitute permanent change. Only the potential is there. This small event could indeed set a course to an adulthood defined by bitterness, self-absorption, and rage. The younger boy briefly merges the projected figure back into himself in a wish expression: "If he was a kid — man! I'd let him have it. I mean, I'd kick the shit out of him!" (Thanya 2001, 47). And yet it is just as possible to imagine that the young boy will release his anger and accept his older playfellow's suggestion to shrug it off and start anew: "We'll make another one, OK?...That's what we'll do, right?" (Thanya 2001, 47). The story ends unresolved and leaves the future open.

"Paper Bird" showcases an interesting array of contrasts to typical narrative patterns in Western short stories. First, a central character enters the story like a Western protagonist but departs from it unchanged. Second, with the writer's departure, so too does the story's point of view shift. Third, there is no climax, no single emotional high point, attached to the writer. Fourth, the writer's outbursts do not fit the pattern of rising action towards a climax. On the contrary, though conflict is central to the story, the repetition of two similar altercations establishes a flat pattern that defines the writer as a rather flat and static character. These fits have happened before and will happen again. Fifth, by means of symbol and shifting point of view, the conflict likewise shifts. In the Western formula, whether the conflict is between two characters, between protagonist and some other opposing force (convention, duty, necessity, society, chance, fate), within a protagonist, or some combination of the three, climax and resolution pertain to the protagonist and almost always bring some kind of change. "Paper Bird" works a conflict between one writer and two boys into a symbolic conflict between the artist and the world, then loads this symbol with divergent meanings attached in different ways to each of the three characters. The 
flat and static characterization of the writer reduces the symbolic conflict to an ironic cliché. The older boy's reaction collapses the symbol back into its literal signification. He is shocked and puzzled, but the incident has no further significance for him. Meanwhile, the younger boy's reaction revitalizes the clichéd conflict between artist and the world and recuperates the symbol to make it meaningful again.

If any character changes, it is the younger boy, and in this sense one might say that "Paper Bird" is his story. Bringing a peripheral character to the center while decentering the story's original central character is an ingenious and satisfying plot device and one which totally opposes Western convention. Furthermore, Thanya's ending creates opposing and mutually exclusive possibilities without favoring or settling on either one. It seems, on the one hand, to give a nod to a Western convention whereby a minor incident in the life of a character generates momentous consequences; yet, on the other hand, it keeps alive the possibility of an alternative outcome: This small incident may turn out to be meaningless and insignificant after all. The writer will likely remain the same as he was from the start and the younger boy may simply remain a child at play. Thus, "Paper Bird" contrasts the typical Western plot-line in one final way: It offers a satisfyingly ambiguous ending by not satisfying the Western urge for resolution.

Similar variations characterize other Phaitoon Thanya stories in the collection translated by Tom Glass (2001) as Paradise Waves. Several of these twelve stories parallel pretty standard Western patterns (especially "Government Stops In" and to some extent "The Red Turtledove"). But a number of them offer irresolution or no resolution, perhaps "The Muddy Path" and "Up on a Cliff" most prominently. Some lack a definitive climax ("The Muddy Path," "Lakeside Paradise Waves"). Others, notably "People on a Bridge" (which exquisitely decenters Western notions of protagonist), build to a climax or emotional high point that coincides with the story's end. The first story in the collection, "Building Sandpiles," has no definitive climax nor resolution. It explicitly ends with all the action still ongoing. Furthermore, its point of view and narrative trajectory are quite similar to "Paper Bird." It centers on a group of boys playing on the beach and eventually encountering a second group of boys. The action moves back and forth between the boys playing in the water and the lone girl from the first group who has been left behind to play on the sand. Their interactions produce slight tensions and conflicts. About three-fourths of the way through the story, the plot line detaches the smallest boy from the first group as he comes back to join the little girl. A new conflict emerges between the two youngest children, but they eventually join forces to build sandcastles together. This shift in view, with its accompanying minor 
conflict and resolution, concludes the story, and the youngest and smallest boy, who plays a small role across the full story, becomes the lone character to experience a small realization of sorts (Thanya 2001, 13-29).

Anchan's “The Beggars," translated by Chancham Bunnag (1996, 54-65), first published in 1990, also shifts perspectives in remarkable and meaningful ways. Told using third-person omniscient point of view, the story gives a portrait of a mixed-poor Bangkok neighborhood that involves a wide cast of characters. It roves here and there, describing the neighborhood and its inhabitants in some detail, sharing specific scenes, and diving into individual characters to reveal private and public thoughts and feelings, often about Grandpa Stump and Grandma Cross-eyed, an old couple familiar to the neighborhood who perform street music for coins. The action, roving here and there, always comes back to the old couple - that is, until it does not. They are certainly the central characters in the plot, more particularly Grandma Cross-eyed, whom most Western readers would likely identify as the protagonist of the story. But the plot, with its repeated returns to the old couple, ultimately shifts away from them. Like the writer in "Paper Bird," they depart from the action in the end-or rather, the action departs from them. Are Grandma Cross-eyed and Grandpa Stump, who are called "the beggars," the same as "The Beggars" named in the story's title? And can Grandma Cross-eyed be considered its protagonist? In the Western sense yes but then again no.

The story opens from the perspective of a young monk who passes the older couple each morning. Up since daybreak, he is always returning to the monastery with his metal alms bowl always full. Grandma Cross-eyed and Grandpa Stump are always just starting their day, their plastic collection bowl always empty. The young monk has often wished to share his food with them, but has always decided against it. On this morning, they confront him and a clever reversal occurs. Initially, he senses that Grandma Cross-eyed might rob him at knife-point, to take the food from his alms bowl. Instead, "the beggars" offer him a meager bag of plain boiled rice and ask for the monk's blessing in exchange for "their act of giving" (Anchan 1996, 55). From this opening scene, the plot advances by means of the perspective of the old couple and other passersby (bickering couples and a young girl with her mother). It centers for a time on a group of artists and then a group of rival writers who draw inspiration from Bangkok street life. The point of view, as it moves to and from individuals or pairs, comes to embody the perspective of the little neighborhood on the whole. By means of this device, Anchan is able to provide an exposé of the old couple, explain the nicknames the neighborhood has conferred upon them (their legal names are unknown), describe their place and status in the neighborhood, the "theme song" they perform and its significance, all while 
taking brief dives into the perspectives of various individuals. Thus, Anchan creates a nuanced and complex characterization of the world in which these characters live.

Eventually the perspective winds back again to the old couple as they gaze upon an especially luxurious car that is stuck in traffic while passing though. From here the perspective turns particularly to Grandma Cross-eyed to share her internal reaction to the appearance of the beautiful girl sitting in the passenger seat of the car. The old and young women make eye contact, the girl beckons for her to approach, and she gives Grandma Cross-eyed a five hundred-baht note (to Grandma, an enormous sum). Bystanders recognize the girl as a famous pop singer. Grandma is "filled with pleasure," showing off her five hundred-baht note while wishing "in her heart" for the pop star to attain "more wealth, more happiness, more success" (Anchan 1996, 64). The story seems to reach a climactic height, but then, most unpredictably, shifts again - to the girl and her driver, peripheral characters come late to the scene, strangers passing through a neighborhood now familiar to readers but not to them. Similar to the shift that occurs in "Paper Bird," the culminating action belongs to the girl. She and her driver continue on their route towards a distant seaside resort, leaving forever behind the street scene and its characters. The driver makes a sarcastic comment, intimating that the pop star performs an act of charity for her own gratification, and the girl responds with an "embarrassed smile" (Anchan 1996, 65). The central characters essentially get decentered by a character whose uncertain realization represents the outcome of the plot.

The routes "Paper Bird" and "The Beggars" take to reach their ends deviate considerably from Western conventions. Neither story ties a climax directly to the conflict of a central character, and the character who enacts the closure of each plot (and who may or may not be changed by it) is not the focal character throughout. The Western formula repeatedly builds tension to climax to resolution through and for a single protagonist. Miss Brill's heightened emotions and false epiphany lead directly to the story's sad end. Jing-mei's return to the piano triggers her deeper understanding and peaceful acceptance that resolve a conflict from decades before. Such resolutions may speak to aspects of our common humanity, but the emphasis lies always upon the individual. Furthermore, "Miss Brill" and "Two Kinds" both suggest a permanent change in the protagonist, while "Paper Bird" and "The Beggars" both end unresolved.

Instead of linking resolution to a protagonist, "Paper Bird" and "The Beggars" do something else, and they do it in common. They surprise Western expectations because neither seems to have a "protagonist" in the Western sense; instead, their outcomes more properly belong to everyone. "Paper Bird" uses shifting point of view to help create symbolic reciprocity, though 
correspondence always remains only potential, and uses a third character, the older boy, as a kind of neutral control figure. "The Beggars" employs the same device to help build intricate correspondences that make everyone a beggar. Monks, street performers, artists, and celebrities all extend something of themselves (alms bowl, collection bowl, artwork, charity), and all receive something in return (sustenance, money, recognition, or gratification). Thus, the title does not ultimately rename Grandma Cross-eyed and Grandpa Stump: "The Beggars" signify multiple characters in the story.

And "The Beggars" layers its economy of giving and receiving well beyond the terms listed above. The young monk, for instance, who opens the action, gives a blessing to the couple out loud, continues to pray for them internally, then shifts his prayer upon himself as a wish for his own ultimate enlightenment. Prayer corresponds to a form of begging. The couple called "the beggars" are also givers (of alms to the monk, music and a kind of identity to the neighborhood, inspiration to artists, gratification for the pop star, and prayers for her success). In fact, "the beggars" may ultimately give more than they receive. Their disabilities provide moralistic material for mothers to daughters. Their kindness to one another serves as a lesson to other bickering couples. Artists make money from sketches of them and one of the writers has won an important literary prize (and with it a chance at fame) for a book called Beggars. Pressed about his subject, he "finally admitted that he found his raw material for the book from this neighborhood" and more particularly, from "our Grandpa and Grandma": "Those two are my cast of characters," he says (Anchan 1996, 6o). And in another clever reversal that points back to the opening scene, Grandma imagines "the long list of things to buy with this big money," including "side dishes to go with the rice when I offer food to a monk" (Anchan 1996, 64).

The encounter between Grandma and the pop star produces nuanced correspondences as well. Before their eyes meet, the pop star's "face had been expressionless, but now she suddenly looked most interested" (Anchan 1996, 63). She explains to her driver: "What is so crazy about giving myself a birthday present by giving a present to another? What a pity you didn't see the old woman's eyes when she saw the five hundred-baht note. Oh, Pat, you should have seen it. It is so true, so natural. I would have given a million baht to get that expression" (Anchan 1996, 64). Her following utterance unexpectedly adds an ironic twist, as the singer imagines what she might further gain from such a present: "You should have had a camera ready to preserve it for me, to show me how to do it when I have to be in front of the camera" (Anchan 1996, 64). The ultimate shift to the pop star serves to reinscribe and reaffirm the story's overarching theme regarding the symbiotic necessity of giving and taking. She gives charity, but she also gives the neighborhood a brief glimpse of luxury and 
beauty. She is a star who shoots across the neighborhood and leaves a temporary mark upon it. The story ends with the couple in the car, on the highway now and far away from the little neighborhood. Their final exchange adds unresolved irony to these interconnected variations on a theme:

Before closing her eyes the girl said in a soft voice: "But it's really a very good thing...that some awfully poor people do exist."

"And make themselves useful for being poor," the man cut in, glad for the opportunity to be sarcastic.

"Silly!" the girl cried, resorting to her favorite exclamation, but this time with an embarrassed smile on her lips. (Anchan 1996, 65)

Perhaps most noteworthy about "The Beggars" is the recognition that conformity to the Western formula relating protagonist to climax would make this story utterly impossible. While "Paper Bird" deviates from Western patterns, it develops in more or less parallel ways until it decenters the writer and displaces climax by attaching an emotional high point onto another character. "The Beggars" makes a very similar shift to end the plot, but the path it takes to get there exchanges the Western pattern of conflict and rising action for recursive and corresponding exchanges of give and take.

Ussiri Thammachot's "On the Route of a Rabid Dog," translated by Chamnongsri L. Rutnin (1996, 8-14), first published in 1978, creates a central character and plot-line that are purely allegorical. The rabid dog and the route it takes represent madness and its ultimate resolution, while two side-plots trace the route of madness through the birth of desire. By spreading the action evenly among its small cast of characters and by narrating from a neutral third-person perspective that does not comment or judge, Thammachot offers a portrait of life and humanity that leaves meaning for readers to decide.

The story's central character is literally the rabid dog itself, who runs along a road leading towards a village, continues running throughout the story, then lies down and dies. This central plot defines a flat route and terminus along which the story divides into two side plots. Each side plot, in turn, offers a variation on the theme of desire centered on a different household along the road that leads to the village. And each variation on the theme, in turn, is depicted as a form of madness, one character in each side story explicitly compared to a rabid dog. The first side story features an older husband, whose sexual desire is endlessly deferred by impotence and whose frustrations and jealousy lead to violence towards his younger wife. She flees their house by the side of the road and he pursues her. When he sees the rabid dog, he orders her to stop. She obeys, stops, and sits down beside the road as the dog passes on. The old 
husband touches her bare shoulder and they go home together. The second side story features an alcoholic father whose desire for drink is thwarted for want of money. His son won't say where the mother has hidden her money and the father chases his son out of the house, then shouts at him when he sees the rabid dog. The boy does not obey because he does not hear. Instead, he runs across the road and directly across the path of the dog, but reaches the other side safely. After the dog passes on, the father crosses the road and picks up the chase.

In themselves, as described above, the various parts of this story are simple indeed. Yet, Thammachot's (1996) careful positioning of elements and plots in relation to one another creates multiple forms of decentering. The story can be described as having two separate and corollary moments of climax, somewhat similar to the dual altercations in Phaitoon Thanya's "Paper Bird." The emotional high point of each side plot is a near-confrontation with the rabid dog. But since confrontation is avoided in each case, each high point is similarly anti-climactic. Furthermore, twice bringing the action to result in a near-miss works to decenter the notion of protagonist within each side plot. Impotent husband and alcoholic father each serve as chief agent in his own plot. But attaching each emotional high point to the character being pursued (wife and son), for whom the dog stands in as a double for each human aggressor, balances and gives equal weight to both pursuers and both pursued. In each side story, the pursued barely misses contact with the rabid dog, while the pursuer is never placed in harm's way. Furthermore, in the sense that rabies is contracted through direct contact with an infected entity, the rabid dog simultaneously embodies both victim and aggressor.

While manipulating his plots to accord equal importance to all of his characters and thus decenter Western notions of protagonist altogether, Thammachot (1996) also introduces some clever variations that imagine alternative outcomes and defer resolution. He orchestrates precise distinctions in the placement of characters in relation to the rabid dog, different kinds of proximity that never amount to contact: The young wife stops before reaching the road and her husband stops upon reaching her. The boy crosses the road in front of the dog, while his father crosses behind. Near-contact is also paralleled by different forms of non-resolution. The first side plot ends back home in the midst of a futile attempt at lovemaking, a potential resolution to the original conflict, arising from the old man's impotence or fleeting virility. Thus, resolution is characterized (for both husband and wife) as sexual anti-climax. The second side plot also ends in the midst of things - the father chasing his son across the fields and away from home on the far side of the road. Thus, this plot never ends at all. As a result, the anti-climax attached to each of the pursued 
(the avoidance of physical encounter with the rabid dog) is paralleled by the irresolution attached to each pursuing character's desire. The old husband does not gain sexual release. The father does not gain relief from the nausea caused by his need for drink.

The displacing and decentering effects created out of the story's numerous consonances and variations can connect to a curious feature built into the story's "central" plot — that is, the story of the rabid dog itself. Rather than plot the dog running through the village, Thammachot (1996) plots it always coming towards the village and arriving only at the very end, when it lies down and dies. The rest of the action, including the side plots, occurs outside or on the way to the village: Two characters act out two unresolved plots along the side of the road along the way to the village. The story is centered by the dog as the symbol of madness, whose final action symbolically prefigures the ultimate resolution of life: In madness or in health, old or young, man or woman, we are released from desire, pain, and the conflicts of life only through the arrival of death. But because death coincides exactly with the dog's arrival to the village, because the arrival of death coincides with an entrance and is not described as a departure, life's ultimate resolution is deferred and decentered once again. The story's title is significant in this regard as well. The other characters have not yet arrived to their ends. They all remain somewhere "on the route."

A close reading of the three stories featured in this analysis reveals not only that they deviate from numerous key elements of the Western formula, but that they do so in related ways. Numerous other Thai stories share family resemblances as well. In several stories from Krisna Asoksin's Sweet Scent of Hay, translated by Wasana Cholasueks Kenman (1993), for instance, the high point or climax concludes the action without subsequent falling action or resolution. Other stories, such as Boonlue's "The Enchanting Cooking Spoon," translated by Herbert P. Phillips and Vinita Atmiyanandana Lawler (in Phillips 1987, 158-188), end with a potential but uncertain reconciliation, or just on the brink of a big decision, as in Asoksin's "Lady Saengkhae" (1993, 41-79). Some end with light ironies or realizations that do not promise to change a character in any significant way. Examples include Phutthapon Angkinan's "Headman Thuj," translated by Herbert P. Phillips and Vinita Atmiyanandana Lawler (in Phillips 1987, 236-239) and Asoksin's "The Electric Fish" (1993, 153-184) and "Lantanas on Doy Mousua" (1993, 219-238). Asoksin's "Lantanas on Doy Mousua" and "A Manipulator" (1993, 81-112) are further examples of stories that shift points of view in surprising and satisfying ways without fixing the perspective or the action on a single protagonist. Each rupture of the Western formula brings these distinct and various Thai stories closer to one another. 
At the same time, all of these stories, "East" and "West," share elements common to the genre of the short story as it has developed all around the world. They all interrelate plots, settings, and characters through the guiding and unifying device of point of view, and no reader from the West could encounter these Thai works in translation without recognizing them as belonging to the genre called "the short story." My own course of inquiry emerged from my experiences as a long-time reader of Western literature, who more recently began encountering Thai short stories. I became struck by how refreshingly satisfying many of these stories were and also by something about them that seemed different from my encounters with short stories hitherto. This difference, I intuited, was not something exotic regarding setting, character, subject, situation, or theme, but about how the stories were happening on the page. From this spark, I widened my exposure to more and more stories, trying to figure out just how they were happening on the page. Soon enough, my attention was drawn to certain recurring elemental features that transformed the way I followed the action.

From this modest comparative study, I will venture to make three general summary observations. One: Plot patterns in many Thai stories again and again reflect a cultural acceptance of the uncertainty and impermanence of existence. Two: Ambiguous, ambivalent, and absent resolutions reflect an awareness that true "epiphanies" - life-altering moments - are quite rare in real life. Three: Fluidities between point of view and character repeatedly evoke an abiding collectivist ethos on the level of craft, regardless of theme or subject. The Western formula, by contrast, through the manner in which it repeatedly reproduces an arc from conflict and rising action to climax and resolution centered on an explicit protagonist, directly parallels dominant Western beliefs regarding the significance of individual experience, of permanent change, and especially the constant focus on the individual ego and its persistence over time.

A major impulse across the essays collected in Disturbing Conventions is to challenge and problematize traditional notions of "Thainess" and "Thai centrism" and to offer theoretical inquiries that can begin to situate Thai literature into a comparative global context. The "Afterword" speaks of a "specific mode of reading [that] requires a new ethics of reading, one in which readers need to be aware of cultural difference and contextualize such difference in an informed way" (Pattarakulvanit et al. 2014, 235). In her "Introduction" to 
the volume, Rachel V. Harrison (2014, 31) writes: "The task of the chapters that follow is to introduce new frames of analysis to the study of Thai literature, hence rendering it accessible to, and bringing it into dialogue with, debates in wider fields." While most of the essays in this important collection draw heavily from Western theoretical approaches, several (notably Feangfu 2014 and Prachakul 2014) also utilize a framework aligned with Western modes of textual analysis to probe issues of "Thai" identity. The present study attempts to move away from insular notions of "Thainess" by adapting an older frame of analysis to a newer set of texts. The intent is not to reinscribe a narrow or naïve or romanticized notion of "Thainess" or even to suggest that these stories are somehow quintessentially Thai. But neither is it to ignore that these stories are Thai stories. Instead, this comparative analysis uncovers a conception of identity that both reflects and reveals the culture out of which the stories arise and is significant on a larger comparative global scale: The protagonist in many Western stories may be characterized as an individual who represents or gives expression to more general widespread human traits, whereas the protagonist in many Thai stories may not be any individual at all, but a collective or diffused representation of humanity itself.

\section{References}

Anchan. 1996. "The Beggars." Translated by Chancham Bunnag. In The S.E.A. Write Anthology of Thai Short Stories and Poems, edited by Nitaya Masavisut and Matthew Grose, 54-65. Chiang Mai: Silkworm Books. Original work published in 1990.

Asoksin, Krisna. 1993. The Sweet Scent of Hay. Translated by Wasana Cholasueks Kenman. Bangkok: Amarin Press.

Charters, Ann. 2015. The Story and Its Writer, gth edition. Boston: Bedford/St. Martin's. Feangfu, Janit. 2014. "Orientalisation From Within and Consuming the Modern

World: Rural-Urban Contact in Thai Popular Literature of the 197os." In Disturbing Conventions: Decentering Thai Literary Studies, edited by Rachel V. Harrison, 111-135. London: Rowman and Littlefield.

Harrison, Rachel. 1999. “'The Son of a Javanese': Translating and Positioning Luuk Chaai Khon Chawaa in a Comparative Literary Frame." South East Asia Research 7 (2):157188. https://doi.org/10.1177/o967828X9900700203.

Harrison, Rachel V. 2014. "Introduction." In Disturbing Conventions: Decentering Thai Literary Studies, edited by Rachel V. Harrison, 1-33. London: Rowman and Littlefield. Kepner, Susan Fulop. 1996. "Introduction." In The Lioness in Bloom: Modern Thai Fiction about Women, edited and translated by Susan Fulop Kepner, 1-39. Berkeley: University of California Press. 
Mansfield, Katherine. 2015. "Miss Brill." In The Story and Its Writer, gth edition, edited by Ann Charters, 862-865. Boston: Bedford/St. Martin's. Original work published in 1920.

Nagavajara, Chetana. 1998. "The Conciliatory Rebels: Aspects of Contemporary Thai Literature." Manusya, Journal of Humanities 1 (1): 72-87. https://doi.org/ 10.1163/26659077-00101006.

Pattarakulvanit, Chusak. 2014. "Chat Kobjitti's The Verdict and Somsong's Appeal." In Disturbing Conventions: Decentering Thai literary Studies, edited by Rachel V. Harrison, 147-167. London: Rowman and Littlefield.

Pattarakulvanit, Chusak, Ben Tran, Suradech Chotiudompant, Rachel V. Harrison, and Ayman El-Desouky. 2014. "Afterword." In Disturbing Conventions: Decentering Thai Literary Studies, edited by Rachel V. Harrison, 233-245. London: Rowman and Littlefield.

Phillips, Herbert P. 1987. Modern Thai Literature: With an Ethnographic Interpretation. Honolulu: University of Hawaii Press.

Prachakul, Nopphorn. 2014. "Luk Isan (A Child of the Northeast): Techniques of Composition and Issues of Ethnic Culture." In Disturbing Conventions: Decentering Thai Literary Studies, edited by Rachel V. Harrison, 105-110. London: Rowman and Littlefield.

Tan, Amy. 2015. "Two Kinds." In The Story and Its Writer, 9th edition, edited by Ann Charters, 1232-1240. Boston: Bedford/St. Martin's. Original work published in 1989. Thammachot, Ussiri. 1996. "On the Route of a Rabid Dog." Translated by Chamnongsri L. Rutnin. In The S.E.A. Write Anthology of Thai Short Stories and Poems, edited by Nitaya Masavisut and Matthew Grose, 8-14. Chiang Mai: Silkworm Books. Original work published in 1978 .

Thanya, Phaitoon. 2001. "Paper Bird." Translated by Tom Glass. In Paradise Waves, 3147. Pathoomtanee: Nakorn Media House. Original work published in 1991. 